\title{
Aumento do potencial de armazenamento refrigerado de nêsperas 'Fukuhara' com o uso de tratamento térmico
}

\author{
Fernando Kazuhiro Edagi(1), Ivan Sestari(1), Fabiana Fumi Sasaki(1), Susana Maria Cabral(1), \\ Juliano Meneghini(1) e Ricardo Alfredo Kluge ${ }^{(1)}$
}

(1)Escola Superior de Agricultura Luiz de Queiroz, Departamento de Ciências Biológicas, Avenida Pádua Dias, oo 11, Caixa Postal 09, CEP 13418-900 Piracicaba, SP. E-mail: fedagi@agrofresh.com, isestari@esalq.usp.br, fsasaki@esalq.usp.br, susymcabral@gmail.com, meneghini87@hotmail.com, rakluge@esalq.usp.br

Resumo - O objetivo deste trabalho foi avaliar a eficiência de tratamentos térmicos no aumento do potencial de frigoconservação de nêsperas 'Fukuhara' e os efeitos desses tratamentos na qualidade e nas propriedades físico-químicas e bioquímicas dos frutos. Os tratamentos de condicionamento térmico foram: armazenamento a $1^{\circ} \mathrm{C}$ durante 60 dias (controle); armazenamento a $5^{\circ} \mathrm{C}$ durante 60 dias (padrão); armazenamento a $5^{\circ} \mathrm{C}$, durante 7 dias, e $1^{\circ} \mathrm{C}$ durante 53 dias; armazenamento a $10^{\circ} \mathrm{C}$, durante 7 dias, e $1^{\circ} \mathrm{C}$ durante 53 dias; aquecimento intermitente, em ciclos de 6 dias a $1^{\circ} \mathrm{C}+1$ dia a $15^{\circ} \mathrm{C}$, durante 60 dias; condicionamento dos frutos a $37^{\circ} \mathrm{C}$, durante 3 horas, e a $1^{\circ} \mathrm{C}$ durante 60 dias; e condicionamento dos frutos a $37^{\circ} \mathrm{C}$, durante 6 horas, e a $1^{\circ} \mathrm{C}$ durante 60 dias. Os frutos foram mantidos a $85-90 \%$ de umidade relativa, durante todo o armazenamento. Foram determinados: firmeza da polpa, índice de escurecimento, acidez titulável, $\mathrm{pH}$, teor de sólidos solúveis, teor de ácido ascórbico, teor de compostos fenólicos, atividade das enzimas fenilalanina amônia-liase (PAL), polifenoloxidase (PPO) e peroxidase (POD) após 15, 30, 45 e 60 dias de armazenamento. Houve correlação entre firmeza de polpa e atividade de POD, após 60 dias de armazenamento refrigerado. $\mathrm{O}$ aquecimento intermitente e o aquecimento a $37^{\circ} \mathrm{C}$, durante 3 horas, foram eficientes no controle do escurecimento interno. Os tratamentos térmicos não evitaram o enrijecimento de polpa. Tratamentos térmicos aumentam o potencial de armazenamento de nêsperas sem alterar as características físico-químicas dos frutos.

Termos para indexação: Eriobotrya japonica, atividade enzimática, compostos fenólicos, condicionamento térmico, escurecimento enzimático, firmeza de polpa.

\section{Potential increasing in the cold-storage of 'Fukuhara' loquat using heat treatments}

\begin{abstract}
The objective of this work was to evaluate the efficiency of heat treatments on the potential improvement of the cold-storage of 'Fukuhara' loquat, and the effects of these treatments on the quality and on physicochemical and biochemical properties of fruits. The treatments applied were: storage at $1^{\circ} \mathrm{C}$ for 60 days (control); storage at $5^{\circ} \mathrm{C}$ for 60 days (standard); storage at $5^{\circ} \mathrm{C}$ for 7 days, and at $1{ }^{\circ} \mathrm{C}$ for 53 days; storage at $10^{\circ} \mathrm{C}$ for 7 days, and at $1{ }^{\circ} \mathrm{C}$ for 53 days; intermittent heat, in cycles of 6 days at $1{ }^{\circ} \mathrm{C}+1$ day at $15^{\circ} \mathrm{C}$, for 60 days; fruit conditioning at $37^{\circ} \mathrm{C}$ for 3 hours, and at $1^{\circ} \mathrm{C}$ for 60 days; and fruit conditioning at $37^{\circ} \mathrm{C}$ for 6 hours, and at $1^{\circ} \mathrm{C}$ for 60 days. The fruits were kept at $85-90 \%$ relative humidity, over the whole storage. The following parameters were determined: pulp firmness, incidence of internal browning, titrable acidity, $\mathrm{pH}$, content of soluble solids, ascorbic acid and phenolic compounds, activity of phenylalanine ammonia-lyase (PAL), polyphenol oxidase (PPO) and peroxidase (POD), in evaluations after 15, 30, 45 and 60 days of storage. There was a correlation between firmness level and POD activity, after 60 days of cold storage. Intermittent heat and at $37^{\circ} \mathrm{C}$ for 3 hours were efficient in controling internal browning in fruit pulp. Heat treatments did not prevent the increase of pulp firmness. Heat treatments increase cold-storage potential of loquat without changing fruit physicochemical properties.
\end{abstract}

Index terms: Eriobotrya japonica, enzymatic activity, phenolic compounds, temperature conditioning, internal browning, pulp firmness.

\section{Introdução}

A nêspera [Eriobotrya japonica (Thurn.) Lindl.] apresenta alto valor comercial e curto período de vida pós-colheita, em razão de perda de água por transpiração, elevada taxa de respiração, alta suscetibilidade a podridão, rápida perda das qualidades nutricionais e sensibilidade dos frutos a baixas temperaturas de armazenamento (Brackmann et al., 2004)

Em geral, o método mais utilizado para prolongar o armazenamento de frutas é a refrigeração. As condições de refrigeração recomendadas para nêsperas são: temperatura entre 0 e $5^{\circ} \mathrm{C}$; umidade relativa entre 90 e $95 \%$; e período de armazenamento de até 60 dias,

Pesq. agropec. bras., Brasília, v.44, n.10, p.1270-1276, out. 2009 
a depender da cultivar (Ding et al., 1998b, 2006; Kader, 2009). Períodos longos de refrigeração, ou a temperaturas muito baixas, ocasionam prejuízos na qualidade dos frutos, em razão da incidência de danos causados pelo frio. Os sintomas de danos pelo frio em nêsperas são o escurecimento da polpa, a perda da suculência, a lignificação de tecidos e o aumento de firmeza (Cai et al., 2006a; Ding et al., 1998a, 2002a; Brackmann et al., 2004), o que torna difícil o armazenamento de nêsperas por longos períodos.

Os danos pelo frio decorrem da atividade de enzimas específicas, responsáveis pela formação de compostos fenólicos e pelo escurecimento destes compostos, tal como a enzima fenilalanina amônia-liase (PAL, EC 4.3.1.24), que é a principal enzima do metabolismo secundário e pode participar, juntamente com outras, na formação "de novo" de lignina, bem como de outros compostos fenólicos (Ding et al., 2002b). Além da PAL, a enzima peroxidase (POD, EC 1.11.1.7) também participa do processo de lignificação (Imberty et al., 1985; Zheng et al., 2000). A POD e a polifenoloxidase (PPO, EC 1.10.3.1) participam também da oxidação de compostos fenólicos, o que pode levar ao escurecimento dos tecidos.

Em razão dos problemas encontrados durante o armazenamento refrigerado, é necessário o desenvolvimento de técnicas que os reduzam e que contribuam para o prolongamento do período de armazenamento e comercialização de nêsperas. Os tratamentos químicos, potencialmente prejudiciais ao homem e ao ambiente, estão sendo cada vez menos utilizados. Assim, tratamentos físicos e alternativos estão sendo pesquisados em várias frutas e podem representar mudança nos tratamentos pós colheita, além de ter boa receptividade entre os produtores e consumidores. Entre esses tratamentos, destacamse os térmicos, como o condicionamento térmico e o aquecimento intermitente, com ar ou água quente, com diferentes métodos de aplicação. Esses tratamentos vêm sendo utilizados para aumentar a resistência dos frutos à baixa temperatura e de aumentar o benefício da refrigeração (Kluge et al., 2006). O efeito dos tratamentos térmicos na conservação refrigerada de nêsperas, no entanto, tem sido pouco estudado. Cai et al. (2006a) verificaram que o condicionamento dos frutos a $5^{\circ} \mathrm{C}$, durante 6 dias antes do armazenamento a $0^{\circ} \mathrm{C}$, reduz significativamente a incidência de danos por frio em nêsperas 'Luoyangqing', em comparação às armazenadas diretamente a $0^{\circ} \mathrm{C}$.
O objetivo deste trabalho foi avaliar a eficiência dos tratamentos térmicos aplicados em nêsperas 'Fukuhara' na redução de danos pelo frio e prolongamento do período de conservação, bem como os efeitos desses tratamentos sobre as características fisico-químicas e bioquímicas dos frutos.

\section{Material e Métodos}

Frutos da cultivar 'Fukuhara' de nespereira foram colhidos em região produtora, no Município de Mogi das Cruzes, SP, e levados para o Laboratório de Fisiologia e Bioquímica Pós-Colheita do Departamento de Ciências Biológicas, da Escola Superior de Agricultura Luiz de Queiroz, em Piracicaba, SP. Os frutos foram selecionados quanto ao tamanho, ponto de maturação e ausência de doenças e danos mecânicos. Após obterse um grupo homogêneo, os frutos foram divididos em sete lotes, acondicionados em embalagens de tereftalato de polietileno (PET) e embalados com filme de policloreto de vinila (PVC) com espessura de $14 \mu$, para posterior aplicação dos tratamentos.

Os tratamentos aplicados foram: armazenamento a $1^{\circ} \mathrm{C}$, durante 60 dias (controle); armazenamento a $5^{\circ} \mathrm{C}$, durante 60 dias (padrão); condicionamento térmico 1 - armazenamento a $5^{\circ} \mathrm{C}$ durante 7 dias, e $1{ }^{\circ} \mathrm{C}$ durante 53 dias; condicionamento térmico 2 - armazenamento a $10^{\circ} \mathrm{C}$ durante 7 dias, e $1{ }^{\circ} \mathrm{C}$ durante 53 dias; aquecimento intermitente - ciclos de 6 dias a $1^{\circ} \mathrm{C}+1$ dia a $15^{\circ} \mathrm{C}$, durante 60 dias; aquecimento 1 - condicionamento dos frutos a $37^{\circ} \mathrm{C}$ durante 3 horas, e $1^{\circ} \mathrm{C}$ durante 60 dias; aquecimento 2 - condicionamento dos frutos a $37^{\circ} \mathrm{C}$ durante 6 horas, e $1^{\circ} \mathrm{C}$ durante 60 dias. Os frutos foram armazenados a $85-90 \%$ de umidade relativa, durante todo o período de armazenamento.

Esses tratamentos foram escolhidos com base em pré-testes. As análises foram realizadas após 15, 30, 45 e 60 dias de armazenamento. O delineamento experimental foi inteiramente ao acaso, em esquema fatorial $7 \times 4$ (sete tratamentos e quatro tempos de armazenamento). Foram utilizadas quatro repetições de 12 frutos por tratamento. Foram avaliados os parâmetros: firmeza da polpa, índice de escurecimento, acidez titulável, $\mathrm{pH}$, teor de sólidos solúveis, teor de ácido ascórbico, teor de compostos fenólicos, e atividade das enzimas fenilalanina amônia-liase, polifenoloxidase e peroxidase (POD), após 15, 30, 45 e 60 dias de armazenamento.

Pesq. agropec. bras., Brasília, v.44, n.10, p.1270-1276, out. 2009 
A firmeza da polpa foi determinada com um penetrômetro manual, com ponteira plana de $5 \mathrm{~mm}$ de diâmetro. Foram efetuadas duas leituras por fruto, em lados opostos da região equatorial, após a remoção de uma pequena parte da casca. Os resultados foram expressos em newtons. Quanto ao índice de escurecimento interno, conforme a área da superfície afetada, os frutos foram classificados em cinco categorias: $0,0 \%$; $1,<5 \% ; 2,5-25 \% ; 3,25-50 \%$; e 4, $>50 \%$. Calculouse o índice de escurecimento da polpa, por meio da fórmula recomendada por Cai et al. (2006b): Índice = ( $\Sigma$ notas x número de frutos afetados $) /(4 \mathrm{x}$ total de frutos da amostra). Os frutos foram considerados não aptos à comercialização, quando atingiram valores superiores a 0,4 de índice ou quando foram atribuídas as notas $3 \mathrm{ou}$ 4 (Cai et al., 2006b).

Para a determinação da acidez titulável, $10 \mathrm{~g}$ da amostra triturada foram colocados em $90 \mathrm{~mL}$ de água destilada. Foi efetuada a titulação potenciométrica com $\mathrm{NaOH} 0,1 \mathrm{~N}$ até $\mathrm{pH} 8,10$, e os resultados foram expressos em percentagem (Carvalho et al., 1990). O pH foi determinado com auxílio de ph-metro de bancada (Tecnal). O teor de sólidos solúveis foi determinado em refratômetro digital (Atago), com os resultados expressos em ${ }^{\circ}$ Brix. O teor de ácido ascórbico foi determinado por titulação, por meio da redução do indicador 2,6-diclorofenol indolfenol-sódio (DCFI) pelo ácido ascórbico. Foram pesados $10 \mathrm{~g}$ da amostra e colocados em tubos de Erlenmeyer com $50 \mathrm{~mL}$ de solução de ácido oxálico. A titulação foi efetuada até atingir a coloração rosada persistente por $15 \mathrm{~s}$. Os resultados foram expressos em miligramas de ácido ascórbico por $100 \mathrm{~g}$ de polpa (Carvalho et al., 1990).

O teor de compostos fenólicos foi determinado de acordo com Singleton \& Rossi (1965). A extração foi realizada em álcool metílico a $80 \%$, e os extratos foram diluídos na proporção de $1 \mathrm{~mL}$ de extrato para $10 \mathrm{~mL}$ de água destilada. Foi adicionado $1 \mathrm{~mL}$ de reagente de Folin-Ciocalteu a $200 \mu \mathrm{L}$ de extrato. Após 8 min do início da reação, foram adicionados $800 \mu \mathrm{L}$ de $\mathrm{Na}_{2} \mathrm{CO}_{3}$ a $7,5 \%$, e a mistura foi agitada em vortex. As amostras foram mantidas no escuro por duas horas, e a leitura foi realizada em espectrofotômetro a $765 \mathrm{~nm}$ de comprimento de onda. A quantidade de fenóis foi calculada pelo equivalente ácido gálico, por meio da comparação com curva padrão, preparada com ácido gálico, em que concentrações variaram de 0 a $500 \mu \mathrm{g}$ por $100 \mathrm{~mL}$. Os resultados foram expressos em miligramas por grama de polpa.
As atividades enzimáticas de PAL, PPO, e POD foram determinadas pelo método de Cai et al. (2006a). Para a extração de PAL, $2 \mathrm{~g}$ de polpa macerada foram adicionados a $8 \mathrm{~mL}$ de tampão borato $0,2 \mathrm{~mol}$ $\mathrm{L}^{-1}$; a amostra foi centrifugada por $20 \mathrm{~min}$ a $4^{\circ} \mathrm{C}$, em $10.000 \mathrm{~g}$, e filtrada em lã de vidro para formar o extrato. Adicionou-se, então, $1 \mathrm{~mL}$ de tampão borato $0,2 \mathrm{~mol} \mathrm{~L}^{-1}$ a $1 \mathrm{~mL}$ de extrato. Em seguida, as amostras foram colocadas em banho-maria a $36^{\circ} \mathrm{C}$, durante $5 \mathrm{~min}$. Foi adicionado $1 \mathrm{~mL}$ de fenilalanina $\left(100 \mathrm{mmol} \mathrm{L}^{-1}\right)$, e os tubos foram incubados em banho-maria a $36^{\circ} \mathrm{C}$, durante 1 hora. Foi adicionado $0,1 \mathrm{~mL}$ de $\mathrm{HCl} 6 \mathrm{~N}$ para parar a reação. A leitura foi realizada em espectrofotômetro, no comprimento de onda de $290 \mathrm{~nm}$. Para extração de PPO e POD, a polpa do fruto foi macerada em nitrogênio líquido. Em $2 \mathrm{~g}$ de polpa macerada, foram adicionados $8 \mathrm{~mL}$ de tampão fosfato de sódio $\left(0,1 \mathrm{~mol} \mathrm{~L}^{-1}, \mathrm{pH} 6\right)$ a $4^{\circ} \mathrm{C}$, centrifugados a $10.000 \mathrm{~g}$ durante $15 \mathrm{~min}$. Para mensurar a atividade de PPO, foi adicionado $0,5 \mathrm{~mL}$ de solução de pirocatecol $\left(100 \mathrm{mmol} \mathrm{L}^{-1}\right)$ a $1,5 \mathrm{~mL}$ de extrato e $1 \mathrm{~mL}$ de tampão fosfato de sódio. Após $2 \mathrm{~min}$ a $25^{\circ} \mathrm{C}$, as leituras foram realizadas em espectrofotometro, em comprimento de onda de $410 \mathrm{~nm}$. Na quantificação da atividade de POD, foi adicionado $0,5 \mathrm{~mL}$ de solução a $1 \mathrm{~mL}$ do extrato, que continha $20 \mathrm{mmol} \mathrm{L}^{-1}$ de peróxido de hidrogênio e tampão fosfato $\left(0,2 \mathrm{~mol} \mathrm{~L}^{-1}\right.$ e pH 6,7$)$, além de $0,5 \mathrm{~mL}$ de solução com $4 \mathrm{mmol} \mathrm{L}^{-1}$ de aminoantipirina e $10 \mathrm{mmol} \mathrm{L}^{-1}$ de pirocatecol. A solução foi incubada em banho-maria a $30^{\circ} \mathrm{C}$, durante $5 \mathrm{~min}$. A reação enzimática foi interrompida com $2 \mathrm{~mL}$ de álcool etílico. A leitura foi realizada em espectrofotômetro, em comprimento de onda de $505 \mathrm{~nm}$. A atividade das três enzimas foi expressa em unidades (U) por grama de polpa, em que 1 U corresponde ao aumento de 0,01 na absorbância por minuto.

Os resultados obtidos foram submetidos à análise de variância, e a diferença mínima significativa foi calculada $(p \leq 0,05)$. Diferenças entre dois tratamentos maiores que a soma de dois erros-padrão foram consideradas significativas.

\section{Resultados e Discussão}

O índice de escurecimento da polpa foi afetado pelos tratamentos, e a incidência foi maior no controle em relação ao padrão $\left(5^{\circ} \mathrm{C}\right)$ e aos tratamentos térmicos, principalmente a partir dos 45 dias de armazenamento (Tabela 1). O escurecimento da polpa é um dos sintomas de dano por frio em nêsperas (Cai et al., 2006b), 
que ocorre quando os frutos são armazenados à temperatura abaixo da mínima de segurança, por longos períodos (Kluge et al., 2001). Frutos tratados com aquecimento intermitente mantiveram baixos índices de escurecimento da polpa, especialmente após 60 dias de armazenamento. $O$ benefício do aquecimento intermitente está no fato de a interrupção das baixas temperatura e a exposição a temperaturas mais altas impedirem a alteração irreversível das membranas celulares, o que promove maior resistência dos tecidos ao frio subsequentemente ao tratamento (Kluge et al., 1996, 2006). Essa maior resistência pode estar relacionada à manutenção da estrutura, à permeabilidade das membranas e ao incremento na atividade de sistemas antioxidantes, que auxiliam na remoção de substâncias tóxicas acumuladas durante o período de exposição à baixa temperatura (Wang et al., 2003; Kluge et al., 2006; Yahia et al., 2007).
Os tratamentos com aquecimento rápido $\mathrm{e}$ armazenamento prévio a 5 e $10^{\circ} \mathrm{C}$ também resultaram em redução na incidência de escurecimento da polpa, o que promoveu maior proteção aos frutos do que o tratamento controle, principalmente até os 45 dias de armazenamento. Esses tipos de tratamentos estimulam os mecanismos de defesa, antes de os frutos serem submetidos ao frio, o que estabelece uma resistência cruzada, com as respostas decorrentes da exposição a temperaturas moderadas ou altas permanecendo atuantes durante a exposição a temperaturas mais baixas (Wang et al., 2003; Kluge et al., 2006). Os principais mecanismos de defesa envolvidos no estabelecimento de maior resistência de frutos tratados termicamente, incluem o estímulo à biossíntese de poliaminas (Mirdehghan et al., 2007) e o estímulo ao aumento da expressão de enzimas antioxidativas (Yahia et al., 2007) e de proteínas de choque térmico (Wang et al., 2004).

Tabela 1. Escurecimento da polpa, atividade da enzima polifenoloxidase, teores de compostos fenólicos, teores de sólidos solúveis, valores de $\mathrm{pH}$, acidez titulável, teores de ácido ascórbico e firmeza da polpa de nêsperas 'Fukuhara' tratadas com diferentes condicionamentos térmicos e armazenadas a $1{ }^{\circ} \mathrm{C}^{(1)}$.

\begin{tabular}{|c|c|c|c|c|c|}
\hline \multirow[t]{2}{*}{ Tratamento } & \multicolumn{5}{|c|}{ Armazenamento a $1^{\circ} \mathrm{C}$ (dias) } \\
\hline & 0 & 15 & 30 & 45 & 60 \\
\hline & \multicolumn{5}{|c|}{ Escurecimento da polpa } \\
\hline Controle & $0,00 \pm 0,00 \mathrm{aD}$ & $0,00 \pm 0,00 \mathrm{aD}$ & $0,13 \pm 0,06 \mathrm{aC}$ & $0,43 \pm 0,08 \mathrm{aB}$ & $1,00 \pm 0,00 \mathrm{aA}$ \\
\hline Padrão & $0,000 \pm 0,00 \mathrm{aC}$ & $0,00 \pm 0,00 \mathrm{aC}$ & $0,07 \pm 0,00 \mathrm{abC}$ & $0,27 \pm 0,10 \mathrm{aB}$ & $0,52 \pm 0,11 \mathrm{bcA}$ \\
\hline $5^{\circ} \mathrm{C}$ por 7 dias & $0,00 \pm 0,00 \mathrm{aC}$ & $0,00 \pm 0,00 \mathrm{aC}$ & $0,10 \pm 0,03 \mathrm{abC}$ & $0,29 \pm 0,08 \mathrm{aB}$ & $0,52 \pm 0,15 \mathrm{bcA}$ \\
\hline $10^{\circ} \mathrm{C}$ por 7 dias & $0,00 \pm 0,00 \mathrm{aC}$ & $0,00 \pm 0,00 \mathrm{aC}$ & $0,05 \pm 0,02 \mathrm{bC}$ & $0,29 \pm 0,16 \mathrm{aB}$ & $0,63 \pm 0,15 \mathrm{bA}$ \\
\hline Intermitente & $0,00 \pm 0,00 \mathrm{aB}$ & $0,00 \pm 0,00 \mathrm{aB}$ & $0,04 \pm 0,00 \mathrm{bB}$ & $0,23 \pm 0,08 \mathrm{aA}$ & $0,27 \pm 0,07 \mathrm{dA}$ \\
\hline $37^{\circ} \mathrm{C}$ por $3 \mathrm{~h}$ & $0,00 \pm 0,00 \mathrm{aC}$ & $0,00 \pm 0,00 \mathrm{aC}$ & $0,05 \pm 0,02 \mathrm{bC}$ & $0,20 \pm 0,10 \mathrm{aB}$ & $0,36 \pm 0,06 \mathrm{cdA}$ \\
\hline \multirow[t]{2}{*}{$37^{\circ} \mathrm{C}$ por $6 \mathrm{~h}$} & $0,00 \pm 0,00 \mathrm{aC}$ & $0,00 \pm 0,00 \mathrm{aC}$ & $0,05 \pm 0,02 \mathrm{bC}$ & $0,23 \pm 0,12 \mathrm{aB}$ & $0,70 \pm 0,04 \mathrm{bA}$ \\
\hline & \multicolumn{5}{|c|}{ Atividade da enzima polifenoloxidase (unidades $\mathrm{mg}^{-1}$ ) } \\
\hline Controle & $0,53 \pm 0,16 \mathrm{aB}$ & $1,57 \pm 0,17 \mathrm{bB}$ & $2,92 \pm 0,48 \mathrm{aAB}$ & $3,48 \pm 0,07 \mathrm{aAB}$ & $5,93 \pm 0,42 \mathrm{aA}$ \\
\hline Padrão & $0,53 \pm 0,16 \mathrm{aB}$ & $2,74 \pm 0,06 \mathrm{aA}$ & $3,51 \pm 0,44 \mathrm{aAB}$ & $3,28 \pm 0,90 \mathrm{aAB}$ & $5,44 \pm 0,22 \mathrm{aA}$ \\
\hline $5^{\circ} \mathrm{C}$ por 7 dias & $0,53 \pm 0,16 \mathrm{aB}$ & $3,98 \pm 0,33 \mathrm{abA}$ & $3,74 \pm 0,56 \mathrm{aA}$ & $4,45 \pm 0,97 \mathrm{aA}$ & $4,48 \pm 0,57 \mathrm{aA}$ \\
\hline $10^{\circ} \mathrm{C}$ por 7 dias & $0,53 \pm 0,16 \mathrm{aC}$ & $2,95 \pm 0,02 \mathrm{abABC}$ & $3,49 \pm 0,46 \mathrm{aA}$ & $1,91 \pm 0,10 \mathrm{aBC}$ & $2,91 \pm 0,55 \mathrm{aAB}$ \\
\hline Intermitente & $0,53 \pm 0,16 \mathrm{aB}$ & $4,26 \pm 0,24 \mathrm{aA}$ & $3,66 \pm 0,67 \mathrm{aA}$ & $1,61 \pm 0,03 \mathrm{aAB}$ & $3,85 \pm 0,37 \mathrm{aA}$ \\
\hline $37^{\circ} \mathrm{C}$ por $3 \mathrm{~h}$ & $0,53 \pm 0,16 \mathrm{aB}$ & $3,08 \pm 0,19 \mathrm{abA}$ & $4,09 \pm 0,70 \mathrm{aA}$ & $5,01 \pm 0,45 \mathrm{aA}$ & $4,74 \pm 0,04 \mathrm{aA}$ \\
\hline \multirow[t]{2}{*}{$37^{\circ} \mathrm{C}$ por $6 \mathrm{~h}$} & $0,53 \pm 0,16 \mathrm{aB}$ & $4,50 \pm 0,38 \mathrm{aA}$ & $2,71 \pm 0,37 \mathrm{aA}$ & $3,81 \pm 0,21 \mathrm{aAB}$ & $3,31 \pm 0,27 \mathrm{aAB}$ \\
\hline & \multicolumn{5}{|c|}{ Teores de compostos fenólicos na polpa $\left(\mathrm{mg} \mathrm{g}^{-1}\right)$} \\
\hline Controle & $0,39 \pm 0,05 \mathrm{aA}$ & $0,62 \pm 0,16 \mathrm{abA}$ & $0,62 \pm 0,16 \mathrm{aA}$ & $0,63 \pm 0,04 \mathrm{abA}$ & $0,63 \pm 0,04 \mathrm{aA}$ \\
\hline Padrão & $0,39 \pm 0,05 \mathrm{aB}$ & $0,74 \pm 0,05 \mathrm{aA}$ & $0,72 \pm 0,03 \mathrm{aA}$ & $0,64 \pm 0,03 \mathrm{abA}$ & $0,66 \pm 0,09 \mathrm{aA}$ \\
\hline $5^{\circ} \mathrm{C}$ por 7 dias & $0,39 \pm 0,05 \mathrm{aB}$ & $0,68 \pm 0,11 \mathrm{abA}$ & $0,63 \pm 0,06 \mathrm{aA}$ & $0,62 \pm 0,08 \mathrm{abA}$ & $0,59 \pm 0,11 \mathrm{aA}$ \\
\hline $10^{\circ} \mathrm{C}$ por 7 dias & $0,39 \pm 0,05 \mathrm{aB}$ & $0,63 \pm 0,08 \mathrm{abA}$ & $0,74 \pm 0,06 \mathrm{aA}$ & $0,66 \pm 0,07 \mathrm{abA}$ & $0,65 \pm 0,08 \mathrm{aA}$ \\
\hline Intermitente & $0,39 \pm 0,05 \mathrm{aC}$ & $0,55 \pm 0,05 \mathrm{abBC}$ & $0,54 \pm 0,11 \mathrm{aBC}$ & $0,70 \pm 0,02 \mathrm{aAB}$ & $0,71 \pm 0,10 \mathrm{aA}$ \\
\hline $37^{\circ} \mathrm{C}$ por $3 \mathrm{~h}$ & $0,39 \pm 0,05 \mathrm{aC}$ & $0,57 \pm 0,07 \mathrm{abB}$ & $0,69 \pm 0,03 \mathrm{aA}$ & $0,56 \pm 0,07 \mathrm{bB}$ & $0,65 \pm 0,03 \mathrm{aAB}$ \\
\hline \multirow[t]{2}{*}{$37^{\circ} \mathrm{C}$ por $6 \mathrm{~h}$} & $0,39 \pm 0,05 \mathrm{aD}$ & $0,48 \pm 0,06 \mathrm{aCD}$ & $0,63 \pm 0,07 \mathrm{aAB}$ & $0,57 \pm 0,06 \mathrm{abBC}$ & $0,73 \pm 0,08 \mathrm{aA}$ \\
\hline & \multicolumn{5}{|c|}{ Teores de sólidos solúveis ( $\left.{ }^{\circ} \mathrm{Brix}\right)$} \\
\hline Controle & $11,40 \pm 0,98 \mathrm{aB}$ & $13,13 \pm 1,06 \mathrm{aAB}$ & $13,38 \pm 0,56 \mathrm{aA}$ & $12,95 \pm 0,48 \mathrm{aAB}$ & $11,75 \pm 1,18 \mathrm{abAB}$ \\
\hline Padrão & $11,40 \pm 0,98 \mathrm{aBC}$ & $13,28 \pm 0,68 \mathrm{aA}$ & $12,23 \pm 0,05 \mathrm{abAB}$ & $11,98 \pm 0,49 \mathrm{aB}$ & $10,20 \pm 0,26 \mathrm{bC}$ \\
\hline $5^{\circ} \mathrm{C}$ por 7 dias & $11,40 \pm 0,98 \mathrm{aA}$ & $12,23 \pm 1,03 \mathrm{abA}$ & $12,63 \pm 0,33 \mathrm{abA}$ & $12,35 \pm 1,24 \mathrm{aA}$ & $11,70 \pm 0,97 \mathrm{abA}$ \\
\hline $10^{\circ} \mathrm{C}$ por 7 dias & $11,40 \pm 0,98 \mathrm{aA}$ & $12,98 \pm 0,85 \mathrm{abA}$ & $12,30 \pm 0,88 \mathrm{abA}$ & $11,75 \pm 0,60 \mathrm{aA}$ & $11,65 \pm 0,78 \mathrm{abA}$ \\
\hline Intermitente & $11,40 \pm 0,98 \mathrm{aA}$ & $11,25 \pm 0,55 \mathrm{bAB}$ & $10,38 \pm 0,46 \mathrm{cB}$ & $12,03 \pm 0,49 \mathrm{aA}$ & $11,50 \pm 1,06 \mathrm{abAB}$ \\
\hline $37^{\circ} \mathrm{C}$ por $3 \mathrm{~h}$ & $11,40 \pm 0,98 \mathrm{aAB}$ & $12,68 \pm 0,44 \mathrm{abA}$ & $12,00 \pm 0,84 \mathrm{abA}$ & $11,50 \pm 0,83 \mathrm{aA}$ & $12,38 \pm 0,56 \mathrm{aA}$ \\
\hline $37^{\circ} \mathrm{C}$ por $6 \mathrm{~h}$ & $11,40 \pm 0,98 \mathrm{aA}$ & $11,90 \pm 0,36 \mathrm{abA}$ & $11,20 \pm 0,96 \mathrm{bcA}$ & $11,75 \pm 0,53 \mathrm{aA}$ & $12,18 \pm 1,05 \mathrm{abA}$ \\
\hline
\end{tabular}


Tabela 1. Continuação...

\begin{tabular}{|c|c|c|c|c|c|}
\hline \multirow[t]{2}{*}{ Tratamento } & \multicolumn{5}{|c|}{ Armazenamento a $1^{\circ} \mathrm{C}$ (dias) } \\
\hline & 0 & 15 & 30 & 45 & 60 \\
\hline & \multicolumn{5}{|c|}{ Valores de $\mathrm{pH}$} \\
\hline Controle & $4,40 \pm 0,10 \mathrm{aC}$ & $4,52 \pm 0,07 \mathrm{aABC}$ & $4,59 \pm 0,07 \mathrm{aAB}$ & $4,45 \pm 0,04 \mathrm{bBC}$ & $4,62 \pm 0,04 \mathrm{aA}$ \\
\hline Padrão & $4,40 \pm 0,10 \mathrm{aB}$ & $4,59 \pm 0,15 \mathrm{aAB}$ & $4,52 \pm 0,01 \mathrm{abAB}$ & $4,67 \pm 0,06 \mathrm{aA}$ & $4,59 \pm 0,05 \mathrm{aAB}$ \\
\hline $5^{\circ} \mathrm{C}$ por 7 dias & $4,40 \pm 0,10 \mathrm{aB}$ & $4,45 \pm 0,12 \mathrm{aAB}$ & $4,51 \pm 0,06 \mathrm{abcAB}$ & $4,62 \pm 0,04 \mathrm{aA}$ & $4,60 \pm 0,09 \mathrm{aA}$ \\
\hline $10^{\circ} \mathrm{C}$ por 7 dias & $4,40 \pm 0,10 \mathrm{aB}$ & $4,56 \pm 0,15 \mathrm{aAB}$ & $4,53 \pm 0,08 \mathrm{abAB}$ & $4,66 \pm 0,07 \mathrm{aA}$ & $4,68 \pm 0,03 \mathrm{aA}$ \\
\hline Intermitente & $4,40 \pm 0,10 \mathrm{aB}$ & $4,41 \pm 0,09 \mathrm{aB}$ & $4,37 \pm 0,03 \mathrm{cB}$ & $4,57 \pm 0,02 \mathrm{abA}$ & $4,58 \pm 0,04 \mathrm{aA}$ \\
\hline $37^{\circ} \mathrm{C}$ por $3 \mathrm{~h}$ & $4,40 \pm 0,10 \mathrm{aC}$ & $4,42 \pm 0,07 \mathrm{aC}$ & $4,48 \pm 0,05 \mathrm{abcBC}$ & $4,56 \pm 0,04 \mathrm{abAB}$ & $4,68 \pm 0,03 \mathrm{aA}$ \\
\hline \multirow[t]{2}{*}{$37^{\circ} \mathrm{C}$ por $6 \mathrm{~h}$} & $4,40 \pm 0,10 \mathrm{aB}$ & $4,45 \pm 0,06 \mathrm{aB}$ & $4,44 \pm 0,09 \mathrm{bcB}$ & $4,57 \pm 0,09 \mathrm{abA}$ & $4,64 \pm 0,05 \mathrm{aA}$ \\
\hline & \multicolumn{5}{|c|}{ Acidez titulável (\%) } \\
\hline Controle & $0,28 \pm 0,05 \mathrm{aA}$ & $0,21 \pm 0,02 \mathrm{aB}$ & $0,20 \pm 0,02 \mathrm{aB}$ & $0,11 \pm 0,01 \mathrm{aC}$ & $0,08 \pm 0,01 \mathrm{aC}$ \\
\hline Padrão & $0,28 \pm 0,05 \mathrm{aA}$ & $0,19 \pm 0,01 \mathrm{aB}$ & $0,19 \pm 0,01 \mathrm{aB}$ & $0,08 \pm 0,01 \mathrm{aC}$ & $0,07 \pm 0,01 \mathrm{aC}$ \\
\hline $5^{\circ} \mathrm{C}$ por 7 dias & $0,28 \pm 0,05 \mathrm{aA}$ & $0,22 \pm 0,03 \mathrm{aB}$ & $0,20 \pm 0,02 \mathrm{aB}$ & $0,09 \pm 0,01 \mathrm{aC}$ & $0,09 \pm 0,04 \mathrm{aC}$ \\
\hline $10^{\circ} \mathrm{C}$ por 7 dias & $0,28 \pm 0,05 \mathrm{aA}$ & $0,19 \pm 0,03 \mathrm{aAB}$ & $0,19 \pm 0,02 \mathrm{aB}$ & $0,08 \pm 0,00 \mathrm{aC}$ & $0,07 \pm 0,00 \mathrm{aC}$ \\
\hline Intermitente & $0,28 \pm 0,05 \mathrm{aA}$ & $0,19 \pm 0,01 \mathrm{aB}$ & $0,22 \pm 0,04 \mathrm{aB}$ & $0,09 \pm 0,01 \mathrm{aC}$ & $0,08 \pm 0,01 \mathrm{aC}$ \\
\hline $37^{\circ} \mathrm{C}$ por $3 \mathrm{~h}$ & $0,28 \pm 0,05 \mathrm{aA}$ & $0,20 \pm 0,02 \mathrm{aB}$ & $0,18 \pm 0,02 \mathrm{aB}$ & $0,09 \pm 0,01 \mathrm{aC}$ & $0,08 \pm 0,01 \mathrm{aC}$ \\
\hline \multirow[t]{2}{*}{$37^{\circ} \mathrm{C}$ por $6 \mathrm{~h}$} & $0,28 \pm 0,05 \mathrm{aA}$ & $0,21 \pm 0,01 \mathrm{aB}$ & $0,19 \pm 0,01 \mathrm{aB}$ & $0,08 \pm 0,01 \mathrm{aC}$ & $0,07 \pm 0,00 \mathrm{aC}$ \\
\hline & \multicolumn{5}{|c|}{ Teores de ácido ascórbico $\left({\left.\mathrm{mg} 100 \mathrm{~g}^{-1}\right)}^{-1}\right.$} \\
\hline Controle & $0,73 \pm 0,13 \mathrm{aA}$ & $0,67 \pm 0,08 \mathrm{aA}$ & $0,70 \pm 0,07 \mathrm{aA}$ & $0,86 \pm 0,21 \mathrm{aA}$ & $0,70 \pm 0,20 \mathrm{aA}$ \\
\hline Padrão & $0,73 \pm 0,13 \mathrm{aA}$ & $0,54 \pm 0,08 \mathrm{aA}$ & $0,68 \pm 0,11 \mathrm{aA}$ & $0,75 \pm 0,09 \mathrm{aA}$ & $0,71 \pm 0,11 \mathrm{aA}$ \\
\hline $5^{\circ} \mathrm{C}$ por 7 dias & $0,73 \pm 0,13 \mathrm{aA}$ & $0,65 \pm 0,05 \mathrm{aA}$ & $0,69 \pm 0,07 \mathrm{aA}$ & $0,74 \pm 0,05 \mathrm{aA}$ & $0,79 \pm 0,05 \mathrm{aA}$ \\
\hline $10^{\circ} \mathrm{C}$ por 7 dias & $0,73 \pm 0,13 \mathrm{aA}$ & $0,61 \pm 0,10 \mathrm{aA}$ & $0,72 \pm 0,04 \mathrm{aA}$ & $0,72 \pm 0,12 \mathrm{aA}$ & $0,75 \pm 0,09 \mathrm{aA}$ \\
\hline Intermitente & $0,73 \pm 0,13 \mathrm{aA}$ & $0,65 \pm 0,05 \mathrm{aA}$ & $0,74 \pm 0,15 \mathrm{aA}$ & $0,70 \pm 0,05 \mathrm{aA}$ & $0,72 \pm 0,06 \mathrm{aA}$ \\
\hline $37^{\circ} \mathrm{C}$ por $3 \mathrm{~h}$ & $0,73 \pm 0,13 \mathrm{aA}$ & $0,59 \pm 0,04 \mathrm{aA}$ & $0,65 \pm 0,05 \mathrm{aA}$ & $0,68 \pm 0,08 \mathrm{aA}$ & $0,76 \pm 0,09 \mathrm{aA}$ \\
\hline \multirow[t]{2}{*}{$37^{\circ} \mathrm{C}$ por $6 \mathrm{~h}$} & $0,73 \pm 0,13 \mathrm{aA}$ & $0,65 \pm 0,05 \mathrm{aA}$ & $0,57 \pm 0,09 \mathrm{aA}$ & $0,62 \pm 0,06 \mathrm{aA}$ & $0,75 \pm 0,08 \mathrm{aA}$ \\
\hline & \multicolumn{5}{|c|}{ Firmeza da polpa (N) } \\
\hline Controle & $3,87 \pm 0,65 \mathrm{aB}$ & $3,97 \pm 0,16 \mathrm{aB}$ & $4,67 \pm 0,57 \mathrm{aAB}$ & $5,34 \pm 0,24 \mathrm{aA}$ & $5,52 \pm 0,23 \mathrm{aA}$ \\
\hline Padrão & $3,87 \pm 0,65 \mathrm{aB}$ & $4,18 \pm 0,35 \mathrm{aAB}$ & $4,17 \pm 0,37 \mathrm{aAB}$ & $4,74 \pm 0,39 \mathrm{aAB}$ & $5,55 \pm 0,52 \mathrm{aA}$ \\
\hline $5^{\circ} \mathrm{C}$ por 7 dias & $3,87 \pm 0,65 \mathrm{aC}$ & $3,69 \pm 0,24 \mathrm{aC}$ & $4,20 \pm 0,27 \mathrm{aBC}$ & $4,86 \pm 0,24 \mathrm{a} A B$ & $5,35 \pm 0,35 \mathrm{aA}$ \\
\hline $10^{\circ} \mathrm{C}$ por 7 dias & $3,87 \pm 0,65 \mathrm{aB}$ & $3,74 \pm 0,29 \mathrm{aB}$ & $4,70 \pm 0,53 \mathrm{aAB}$ & $4,95 \pm 0,46 \mathrm{aA}$ & $5,01 \pm 0,23 \mathrm{aA}$ \\
\hline Intermitente & $3,87 \pm 0,65 \mathrm{aB}$ & $3,76 \pm 0,33 \mathrm{aB}$ & $4,25 \pm 0,19 \mathrm{aA}$ & $4,81 \pm 0,31 \mathrm{aAB}$ & $4,93 \pm 0,64 \mathrm{aAB}$ \\
\hline $37^{\circ} \mathrm{C}$ por $3 \mathrm{~h}$ & $3,87 \pm 0,65 \mathrm{aA}$ & $3,79 \pm 0,36 \mathrm{aA}$ & $4,80 \pm 0,51 \mathrm{aA}$ & $4,96 \pm 0,38 \mathrm{aA}$ & $4,98 \pm 0,55 \mathrm{aA}$ \\
\hline $37^{\circ} \mathrm{C}$ por $6 \mathrm{~h}$ & $3,87 \pm 0,65 \mathrm{aC}$ & $4,02 \pm 0,18 \mathrm{aC}$ & $4,76 \pm 0,49 \mathrm{aA}$ & $4,93 \pm 0,20 \mathrm{aAB}$ & $4,71 \pm 0,33 \mathrm{aBC}$ \\
\hline
\end{tabular}

Com o aumento da incidência de escurecimento da polpa, esperava-se aumento na atividade da PPO e uma diminuição no teor de compostos fenólicos, o que não foi observado (Tabela 1).

A PPO, além da forma ativa presente no citossol, apresenta formas latentes, presentes tanto no citossol quanto em plastídios, isoladas do restante da célula (Sellés-Marchart et al., 2006). A manutenção dessa enzima na forma latente ou a não descompartimentalização dos plastídios, durante o armazenamento refrigerado, pode ter causado a oscilação da atividade de PPO nesse experimento. $\mathrm{O}$ estresse causado aos frutos, em razão do armazenamento refrigerado, pode ter ativado o metabolismo secundário das células, que é uma das rotas formadoras de compostos fenólicos (Ding et al., 2001), o que explica o incremento no teor de fenóis totais, presentes nos frutos de nêspera ao longo do armazenamento (Tabela 1).
O teor de sólidos solúveis apresentou pouca oscilação durante o armazenamento (Tabela 1), o que é típico de frutos não climatéricos (Zhang et al., 1990). Os valores de $\mathrm{pH}$ aumentaram durante $\mathrm{o}$ armazenamento refrigerado, e a acidez titulável consequentemente diminuiu, o que pode ser explicado pela redução no teor de ácidos orgânicos. O teor de ácido ascórbico não apresentou grande variação nas avaliações durante a refrigeração. As diferenças entre os tratamentos não ultrapassaram o limite de dois erros-padrão e, portanto, durante os 60 dias de armazenamento não foi observado efeito significativo dos condicionamentos térmicos sobre as características físico-químicas de nêsperas.

Durante o armazenamento refrigerado, foi observado aumento na firmeza da polpa em todos os tratamentos (Tabela 1), causado pela lignificação do tecido (Zheng et al., 2000), catalisada principalmente pelas enzimas fenilalanina amônia-liase (PAL) e peroxidase (POD). $\mathrm{O}$ aumento da firmeza da polpa foi observado após 
30 dias de armazenamento a $1^{\circ} \mathrm{C}$. Entretanto, aos 15 dias de refrigeração, ocorreu um aumento de atividade da PAL. Esse aumento na atividade de PAL pode ser consequência do aumento na produção de monômeros de lignina (Boudet, 2000). Em reação catalizada pela POD, os monômeros de lignina são polimerizados, aderem à parede celular e causam o enrijecimento da polpa (İpekçi et al., 1999).

Alguns autores caracterizam o enrijecimento da polpa como um sintoma da senescência do fruto, ao invés de dano por frio (Cai et al., 2006c). Tal afirmação pode ser reforçada pelos resultados deste trabalho, pois, após 60 dias de armazenamento, foi possível observar correlação 0,924 entre a atividade de POD com os valores de firmeza da polpa (Tabela 1). A POD, além de estar relacionada à polimerização de monômeros de lignina, é uma enzima sinalizadora de senescência (Cano et al., 1995; Singh \& Dwivedi, 2008).

\section{Conclusões}

1. O aquecimento intermitente e o aquecimento a $37^{\circ} \mathrm{C}$ durante três horas diminuem o escurecimento interno de polpa.

2. Os tratamentos térmicos não são eficientes no controle do enrijecimento de polpa em nêsperas 'Fukuhara'.

3. Tratamentos térmicos aumentam o potencial de armazenamento de nêsperas sem alteração nas características físico-químicas das frutas.

\section{Agradecimentos}

À Fundação de Amparo à Pesquisa do Estado de São Paulo, pelo apoio financeiro e concessão de bolsa; à Associação Frutícola do Alto Tietê, pela doação dos frutos para os experimentos.

\section{Referências}

BOUDET, A.M. Lignins and lignification: selected issues. Plant Physiology and Biochemistry, v.38, p.81-96, 2000.

BRACKMANN, A.; SAQUET, A.A.; CERETTA, M.; STORCK, L. Armazenamento de nêsperas (Eriobotrya japonica Lindl.) cv. Mizuho em atmosfera modificada. Revista Científica Rural, v.9, p.18-24, 2004.

CAI, C.; LI, X.; CHEN, K.S.; SHAN, L. Acetylsalicylic acid alleviates chilling injury of postharvest loquat (Eriobotrya japonica Lindl.) fruit. European Food Research and Technology, v.223, p.533-539, 2006a.
CAI, C.; XU, C.J.; LI, X.; FERGUSON, I.; CHEN, K.S. Accumulation of lignin in relation to change in activities of lignification enzymes in loquat fruit flesh after harvest. Postharvest Biology and Technology, v.40, p.163-169, 2006b.

CAI, C.; XU, C.J.; SHAN, L.L.; LI, X.; ZHOU, C.; ZHANG, W.; FERGUSON, I.; CHEN, K. Low temperature conditioning reduces postharvest chilling injury in loquat fruit. Postharvest Biology and Technology, v.41, p.252-259, 2006c.

CANO, M.P.; ANCOS, B. de; LOBO, G. Peroxidase and polyphenoloxidase activities in papaya during postharvest ripening and after freezing/thawing. Journal of Food Science, v.60, p.815-817, 1995.

CARVALHO, C.R.L.; MANTOVANI, D.M.B.; CARVALHO, P.R.N.; MORAES, R.M. Análises químicas de alimentos. Campinas: Instituto de Tecnologia de Alimentos, 1990. 121p. (Manual técnico).

DING, C.K.; CHACHIN, K.; HAMAUZYU, Y.; UEDA, Y.; IMAHORI, Y. Effects of storage temperatures on physiology and quality of loquat fruit. Postharvest Biology and Technology, v.14, p.309-315, 1998a.

DING, C.K.; CHACHIN, K.; UEDA, Y.; IMAHORI, Y. Purification and properties of polyphenol oxidase from loquat fruit. Journal of Agricultural and Food Chemistry, v.46, p.4144-4149, 1998b.

DING, C.K.; CHACHIN, K.; UEDA, Y.; IMAHORI, Y.; WANG, C.Y. Metabolism of phenolic compounds during loquat fruit development. Journal of Agriculture and Food Chemistry, v.49, p.2883-2888, 2001.

DING, C.K.; CHACHIN, K.; UEDA, Y.; IMAHORI, Y.; WANG, C.Y. Modified atmosphere packaging maintains postharvest quality of loquat fruit. Postharvest Biology and Technology, v.24, p.341-348, 2002a.

DING, C.K.; WANG, Y.C.; GROSS, K.C.; SMITH, D.L. Jasmonate and salicylate induce the expression of pathogenesis-related-protein genes and increase resistance to chilling injury in tomato fruit. Planta, v.214, p.895-901, 2002b.

DING, Z.S.; TIAN, S.P.; WANG, Y.S.; LI, B.Q.; CHAN, Z.; HAN, J.; XU, Y. Physiological response of loquat fruit to different storage conditions and its storability. Postharvest Biology and Technology, v.41, p.143-150, 2006.

IMBERTY, A.; GOLDBERG, R.; CATESSON, A.M. Isolation and characterization of populus isoperoxidases involved in the last step of lignin formation. Planta, v.164, p.221-226, 1985.

İPEKÇİ, Z.; OĞRAS, T.; BAJROVIC, K.; KAZAN, K.; GÖZÜKIRMIZl, N.; BOYDAK, M.; TANK, T.; AKALP, T.; ÖZDEN, Ö.; ÇALIKOĞLU, M.; TUNÇTANER, K.; TULUKÇU, M.; BALKAN, H.; TANRIYAR, H. Reduced leaf peroxidase activity is associated with reduced lignin content in transgenic poplar. Plant Biotechnology, v.16, p.381-387, 1999.

KADER, A.A. Loquat: recommendations for maintaining postharvest quality. Davis: University of California, 2008. Disponível em: <http://postharvest.ucdavis.edu/Produce/ Producefacts/Fruit/loquat.shtml>. Acesso em: 13 mar. 2009.

KLUGE, R.A.; AZEVEDO, R.A. de; JOMORI, M.L.L.; EDAGI, F.K.; JACOMINO, A.P.; GAZIOLA, S.A.; AGUILA, J.S. del. Efeitos

Pesq. agropec. bras., Brasília, v.44, n.10, p.1270-1276, out. 2009 
de tratamentos térmicos aplicados sobre frutas cítricas armazenadas sob refrigeração. Ciência Rural, v.36, p.1388-1396, 2006.

KLUGE, R.A.; HOFFMANN,A.; NACHTIGAL, J.C.; BILHALVA, A.B.; FACHINELLO, J.C. Aquecimento intermitente em pêssegos 'Br-6' frigoconservados. Pesquisa Agropecuária Brasileira, v.31, p.543-547, 1996.

KLUGE, R.A.; SCARPARE FILHO, J.A.; JACOMINO, A.P.; PEIXOTO, C.P. Distúrbios fisiológicos em frutos. 2.ed. Piracicaba: FEALQ, 2001. 58p.

MIRDEHGHAN, S.H.; RAHEMI, M.; MARTÍNEZ-ROMERO, D.; GUILLÉN, F.; VALVERDE, J.M.; ZAPATA, P.J.; SERRANO, M.; VALERO, D. Reduction of pomegranate chilling injury during storage after heat treatment: role of polyamines. Postharvest Biology and Technology, v.44, p.19-25, 2007.

SELLÉS-MARCHART, S.; CASADO-VELA, J.; BRU-MARTÍNEZ, R. Isolation of a latent polyphenol oxidase from loquat fruit (Eriobotrya japonica Lindl.): kinetic characterization and comparison with the active form. Archives of Biochemistry and Biophysics, v.446, p.175-185, 2006.

SINGH, R.; DWIVEDI, U.N. Effect of ethrel and 1-methylcyclopropene (1-MCP) on antioxidants in mango (Mangifera indica var. Dashehari) during fruit ripening. Food Chemistry, v.111, p.951-956, 2008.
SINGLETON, V.L.; ROSSI JUNIOR, J.A. Colorimetry of total phenolics with phosphomolybdic-phosphotungstic acid reagents. American Journal of Enology and Viticulture, v.16, p.144-158, 1965.

WANG, W.X.; VINOCUR, B.; ALTMAN, A. Plant responses to drought, salinity and extreme temperatures: towards genetic engineering for stress tolerance. Planta, v.218, p.1-14, 2003.

WANG, W.X.; VINOCUR, B.; SHOSEYOV, O.; ALTMAN, A. Role of plant heat-shock proteins and molecular chaperones in the abiotic stress response. Trends in Plant Science, v.9, p.244-252, 2004.

YAHIA, E.M.; SOTO-ZAMORA, G.; BRECHT, J.K.; GARDEA, A. Postharvest hot air treatment effects on the antioxidant system in stored mature-green tomatoes. Postharvest Biology and Technology, v.44, p.107-115, 2007.

ZHANG, H.Z.; PENG, S.A.; CAI, L.H.; FANG, D.Q. The germoplasm resources of the genus Eriobotrya with special reference on the origin of E. japonica Lindl. Acta Horticulturae Sinica, v.17, p.5-12, 1990.

ZHENG, Y.H.; LI, S.Y.; XI, Y.F.; PENG, S.A. Changes of cell wall substances in relation to flesh woodiness in cold-stored loquat fruits. Acta Phytophysiologica Sinica, v.26, p.306-310, 2000.

$\overline{\text { Recebido em } 5 \text { de junho de } 2009 \text { e aprovado em } 29 \text { de setembro de } 2009}$ 